\title{
METHOD FOR DETERMINATION OF LOAD-BEARING CAPACITY OF HAUNCHED ZONES MADE OF IPE-TYPE ROLLED
}

\author{
METOD ODREĐIVANJA NOSIVOSTI ZONE OJAČANJA (VUTA) IZRAĐENIH \\ OD IPE TOPLO VALJANIH PROFILA
}

Marin VASSILEV

\author{
PRETHODNO SAOPŠTENJE \\ PRELIMINARY REPORT \\ UDK:692.232.046.3 \\ doi:10.5937/GRMK1903031
}

\section{INTRODUCTION}

Despite the extensive application of portal frames for single-storey buildings with steel structures, there are still some aspects of their stability that require additional clarification. No codified practical method is given in EN 1993-1-1 [1] for lateral-torsional stability verification of rafters in the haunched portions loaded by hogging bending moments. It seems that, within the code, there are only two possible approaches: the general method for lateral (clarified in details in [5], [6] and [7]) and lateral torsional buckling (§6.3.4 of [1]) and geometrically and materially nonlinear analysis with imperfections (GMNIA) as regulated by $\S 2.5$ and Annex C of EN 1993-1-5 [2] However, both methods seem quite complicated and cumbersome for practical use.

The lateral-torsional stability of rafters seems an even more complicated problem, taking into account the haunched portions, the negative (hogging) bending moments and the specific restraint conditions with lateral supports at the top (tensile) flange only (the so-called 'fly bracing' is unconventional for Bulgarian practice). Therefore, the author has recently carried out an extensive research and theoretical analyses in the above context. In a recent publication [3] the general method for lateral buckling has been discussed in details with emphasis on the specific issues of its application to the frame lateral stability, namely the complex modelling, the correct identification of the relevant buckling mode and the selection of adequate criterion for load-carrying resistance. The application of the geometrical and material nonlinear analysis with imperfections (GMNIA) is also clarified and discussed in [3]. Some well known simplified methods for out-of-plane stability verification of rafters and haunches are presented as well. However they consider restraints at the bottom flanges too, and thus appear unsuitable for local practice. Nevertheless, some brief description of GMNIA is presented.

The third type of analysis, GMNIA, is also carried out automatically. The model with shell FE is generated and linear buckling analysis is initially performed. The first overall out-of-plane buckling mode is used to obtain the initial imperfections pattern, scaled according to \$5.3.4 of EN 1993-1-1 [1]. A revised model is thus generated. Material nonlinearity is based on bilinear constitutive law with isotropic strain hardening. The load-carrying capacity of the frame is assumed to correspond to the ultimate state criterion 'attainment of the maximum load'. The stressed state and the failure mode are also analysed. The software used is ABAQUS nonlinear FE software (Abaqus 2016) [6]. A typical picture at limit state is illustrated in Figure 1.

The primary objective of this study was to adapt, propose and confirm a simplification of widely spread practical method for calculating buckling capacity of haunch. The latter is based on buckling verification of equivalent compressed strut and it is illustrated in Fig. 2.

Marin Vassilev, Department of Steel and Timber Structures, UACEG, Sofia 

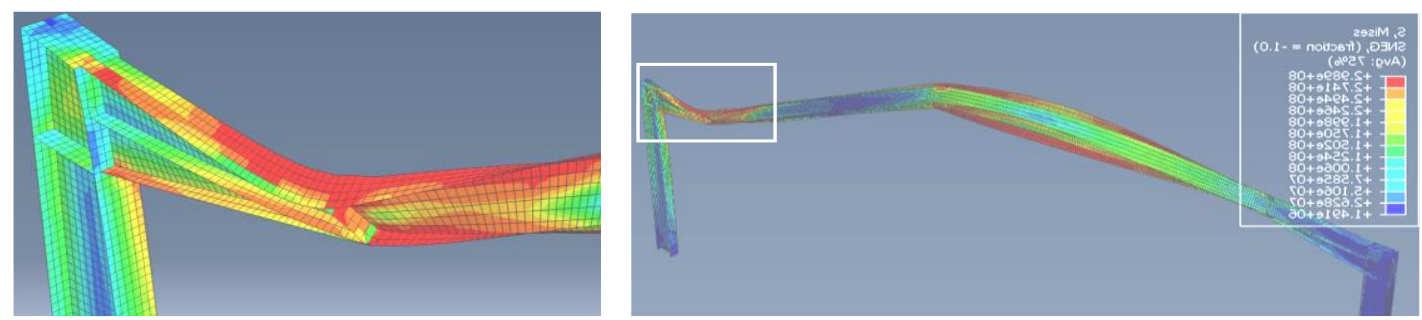

Fig. 1. Typical frame failure mode obtained by GMNIA.

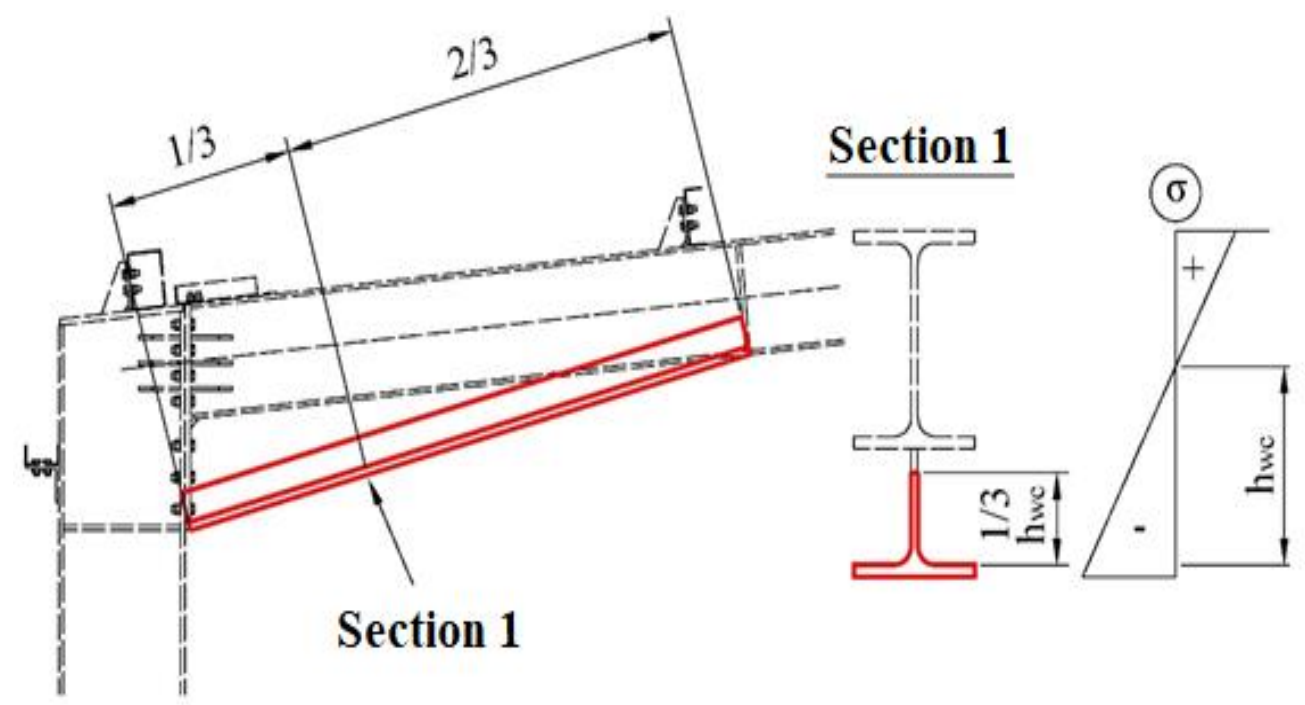

Fig. 2. Equivalent compressed strut simplified model

In this well-known simplified model from literature [4], an equivalent compressed strut is defined in section 1 as illustrated in the figure. The axial compression force on the strut is determined in the same section. The lateral buckling verification of the haunched portion is then replaced by out-of-plane flexural buckling check of the strut. Buckling length coincides with the geometric length of the member. The method seems very simple, however requires a fly-brace restraint at the haunch end [4](both flanges at both ends of element must be restraint for out-of-plane movement). Nevertheless, the method is also applied in this study with a view to be eventually adapted to the typical practice in Bulgaria, where fly bracing is absent. Imperfections are considered according to [1] when calculating buckling compression capacity of T-strut. Considered haunches are identical and composed of steel grades - S235, S275 and S355.

\section{NUMERICAL ANALYSIS OF METHODOLOGY FOR HAUNCH VERIFICATION}

An analysis is made, independently upon the simplified methodology with an equivalent compressed strut, of haunched zones consisting a profile of type IPE and a haunch cut from the base profile, with an initial height coinciding with the initial height of the beam projected on the column. Examined lengths for the haunched section are between $1 \mathrm{~cm}$ and $500 \mathrm{~cm}$. Thus, it can be said that all possible cases are considered in full-wall frames made of rolled profiles (for example, if we decide that the haunch length is $10 \%$ of the frame opening and is 4 meters long, it means that the frame should have an opening of 40 meters- on such an opening a IPE-type rolled profile can hardly be applied). The geometry of the options considered is shown schematically in Figure 3.

The purpose of the upcoming analysis is to draw out simplified formulas to apply the simplified method with an equivalent pressed rod, especially for the IPE-type beam and the haunch with the same profile described in Figure 3. 


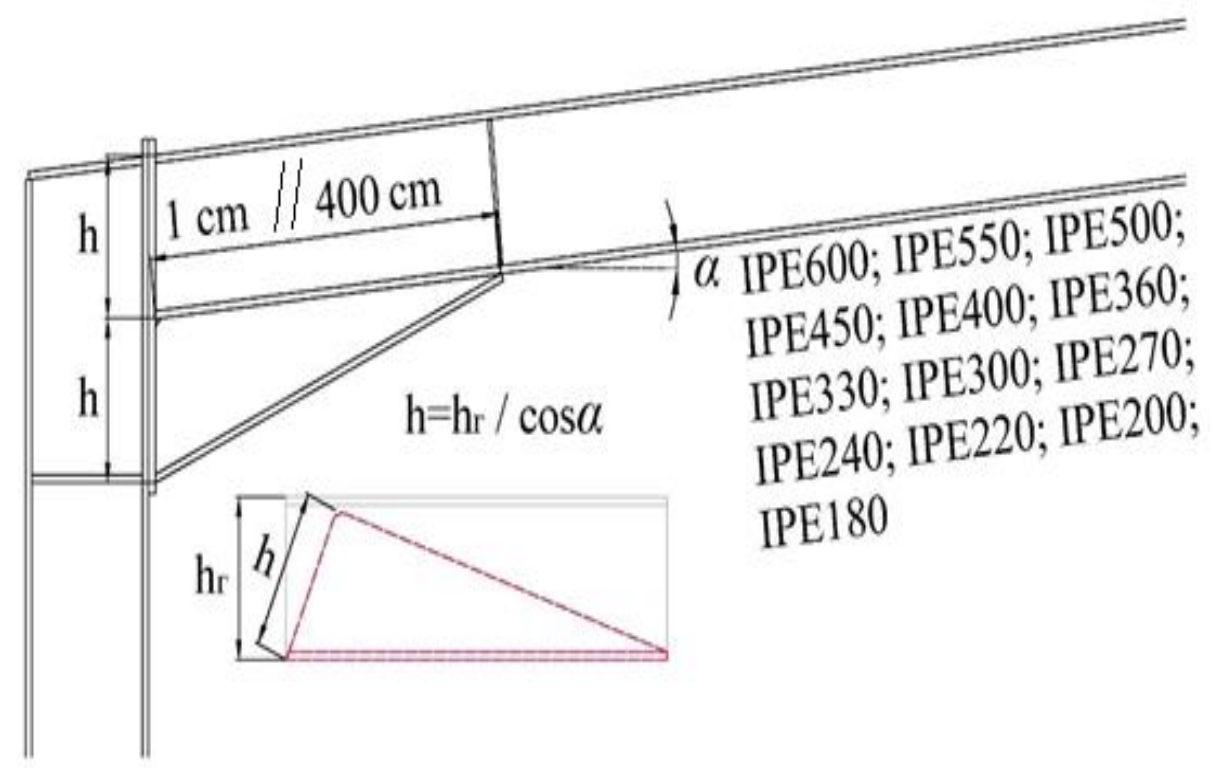

Fig. 3. Analyzed models

\subsection{Analysis of haunch buckling capacity}

We will initially evaluate the effect of the size of the equivalent compressed strut. Its magnitude depends on the compressed part of the stem, respectively the eccentricity of the force, reduced at some distance from the center of gravity of the cross section:

$$
e=M / N[\mathrm{~cm}]
$$

Figure 4 illustrates a relationship between the bearing capacity of the $T$-section equivalent profile $\left(N_{b, R d, z}\right)$ for the various rolled profiles, in function of eccentricity.
In Figure 4, the illustrated dependence is done for a $350 \mathrm{~cm}$ long haunched section, but for practically different lengths, the tendency remains. Only the small eccentricities have some effect on the load bearing capacity of the element - at $e<200$. The typical eccentricity of the frames examined by about $10 \%$ slope is about $300 \mathrm{~cm}$ (eg $1000 \mathrm{kNm}$ bending moment and approximately $300 \mathrm{kN}$ pressure in section of the third). Although the eccentricity does not have an enormous importance - about $10 \%\left(\max N_{b, R d, z} / \min N_{b, R d, z} \sim 1,1\right)$, in order to be safe for the next reasoning, we will perform a detailed analysis with an eccentricity value of about 300 $\mathrm{cm}$ (this way we will work with the "lower" values of the load bearing capacity).

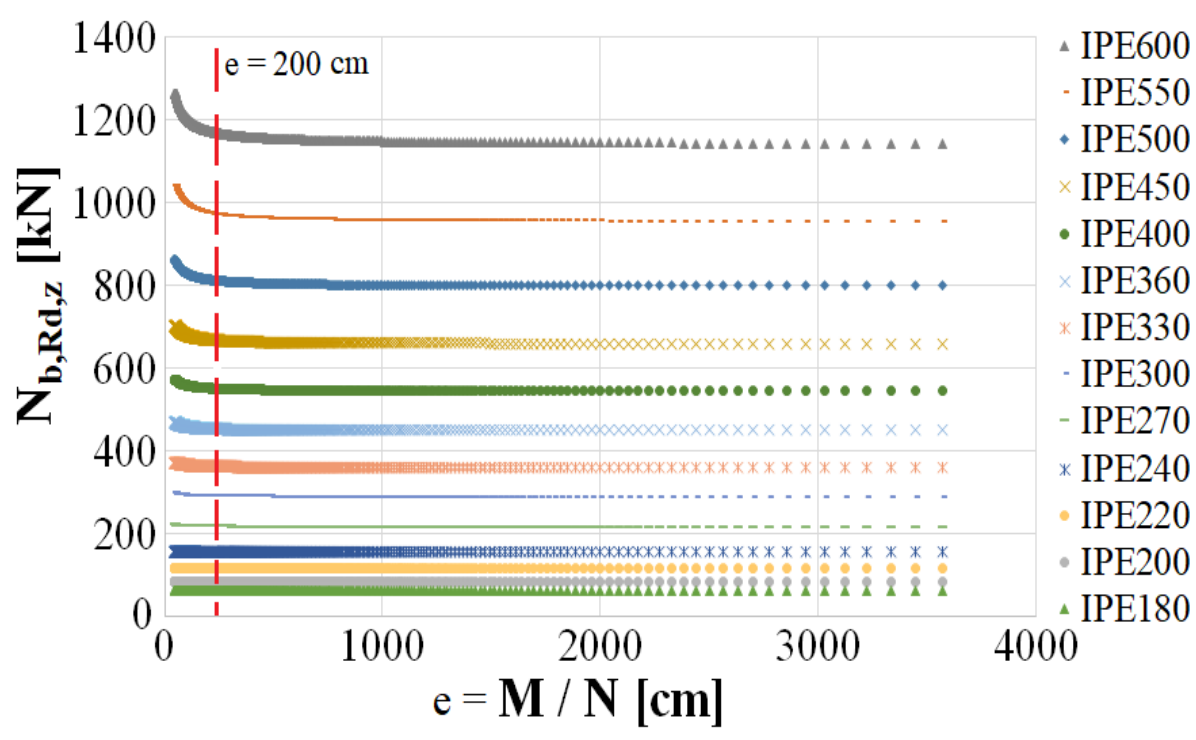

Fig. 4. Compression capacity of equivalent T-struts in function of eccentricity "e" 
In order to see the load-bearing curves for the different profiles "more generally", an analysis according to the simplified method for an equivalent compressed $T$ profile for the lengths from $1 \mathrm{~cm}$ to $2000 \mathrm{~cm}$ will be performed. The dependence between the load-bearing capacity of the equivalent profiles and the length of the haunch is illustrated in Fig. 5 for various rolled profiles made of $S 235$ steel grade.

At very small section lengths, the T-profiles are so non-slender that they can not buckle. Absolutely identical calculations were made for the relevant profiles, but made up of $S 275$ steel grade (Figure 6).

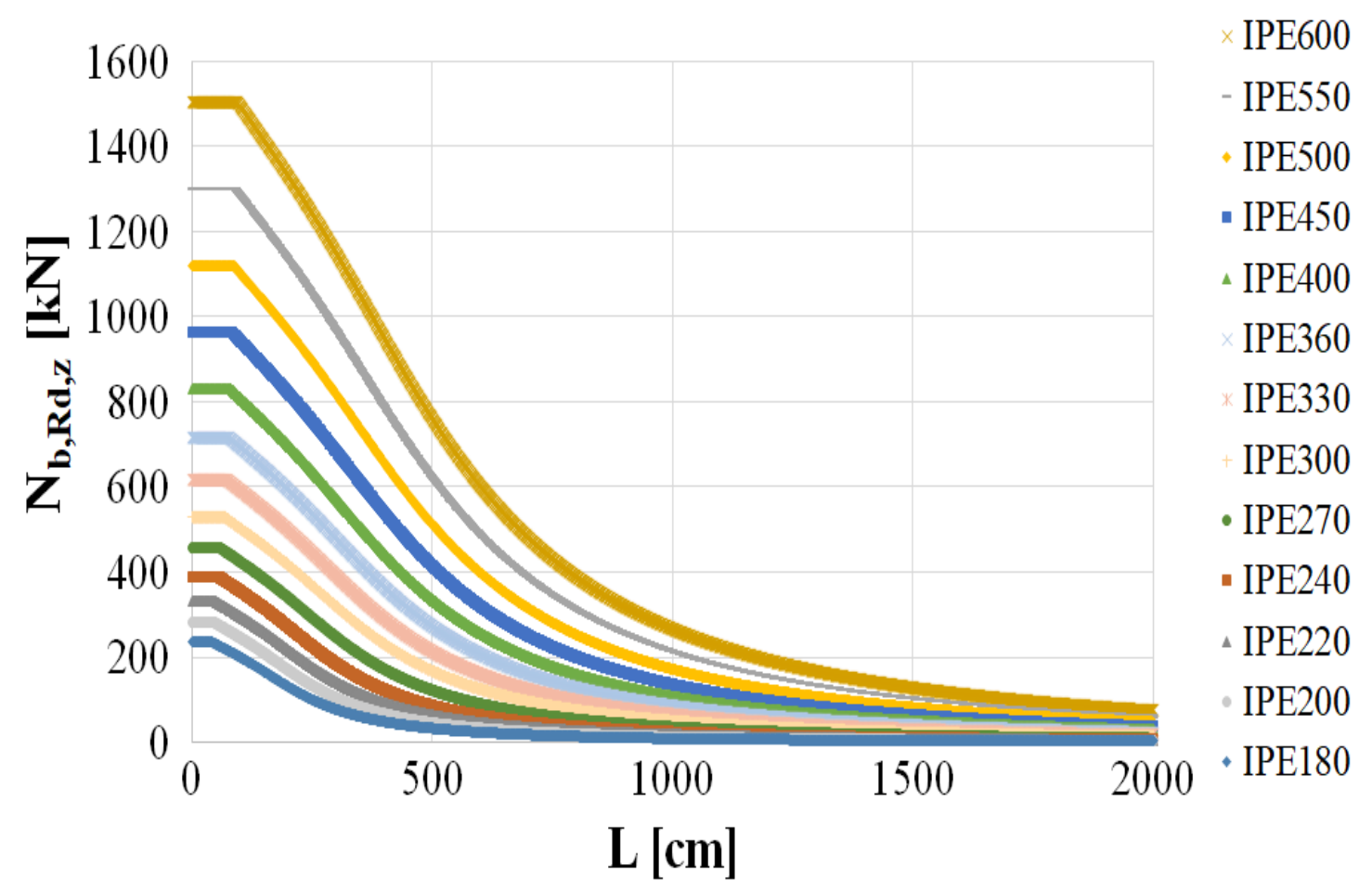

Fig. 5. Compression capacity of equivalent T-struts with different lengths composed of steel grade S235

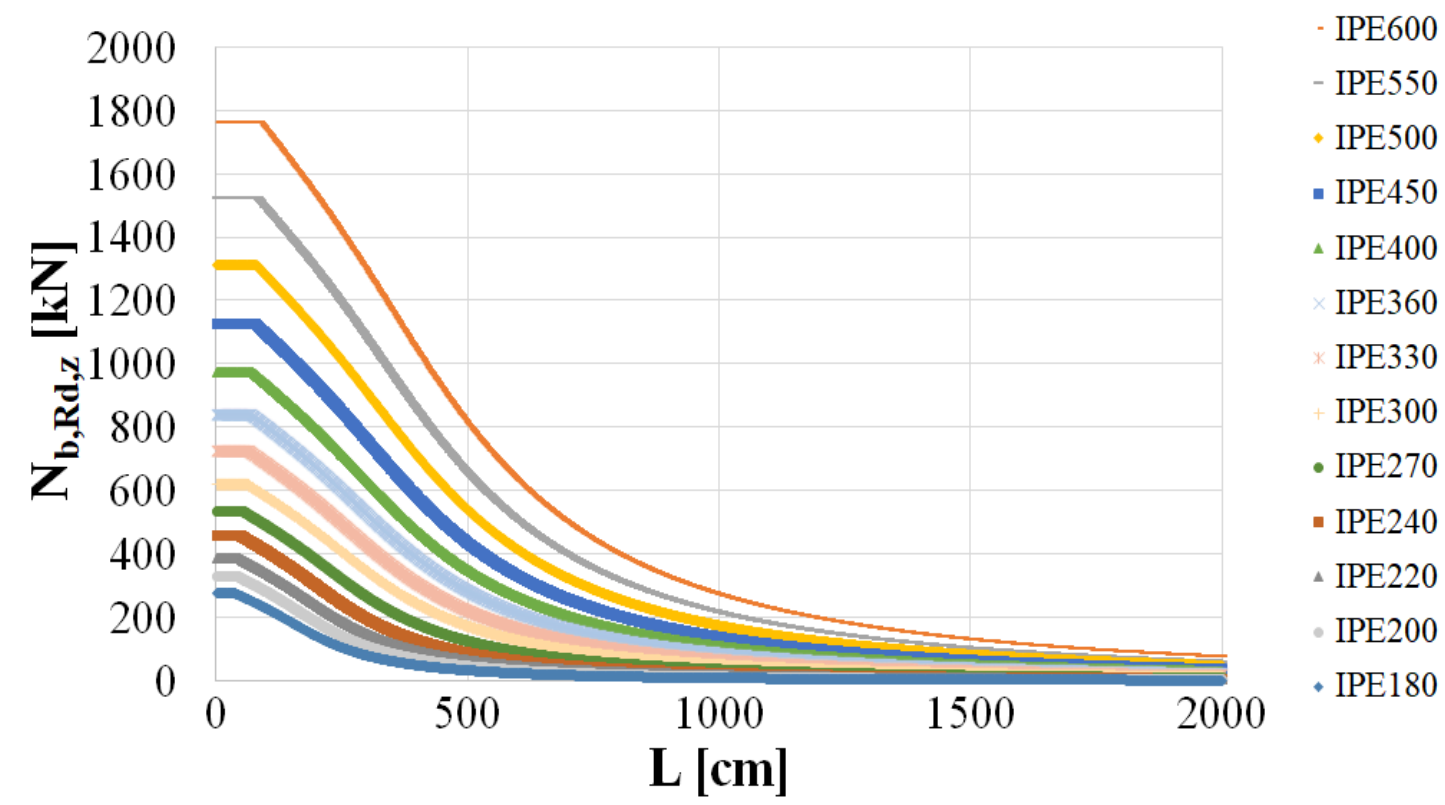

Fig. 6. Compression capacity of equivalent T-struts with different lengths composed of steel grade S275 
Finally, the analysis is also performed for equivalent bevelled haunched sections, this time the used steel grade is $S 355$ (Figure7).

Hence, after mathematical operations and transformations for the first $\mathbf{4}$ meters, from these curves and the maximum value limit, formulas were derived for the entire range of IPE profiles shown in Figure 5, Figure 6 and Figure 7:

$$
\begin{aligned}
& N_{b, R d, z, S 235}=-1,6 \times 10^{-4} \times h^{1,105} \times L+0,06 \times h^{1,600} \leq 2,95 \times h-330[\mathrm{kN}] \\
& N_{b, R d, z, S 275}=-1,3 \times 10^{-4} \times h^{1,175} \times L+0,06 \times h^{1,630} \leq 3,45 \times h-385[\mathrm{kN}] \\
& N_{b, R d, z, S 355}=-1,0 \times 10^{-4} \times h^{1,280} \times L+0,06 \times h^{1,670} \leq 4,45 \times h-500[\mathrm{kN}]
\end{aligned}
$$

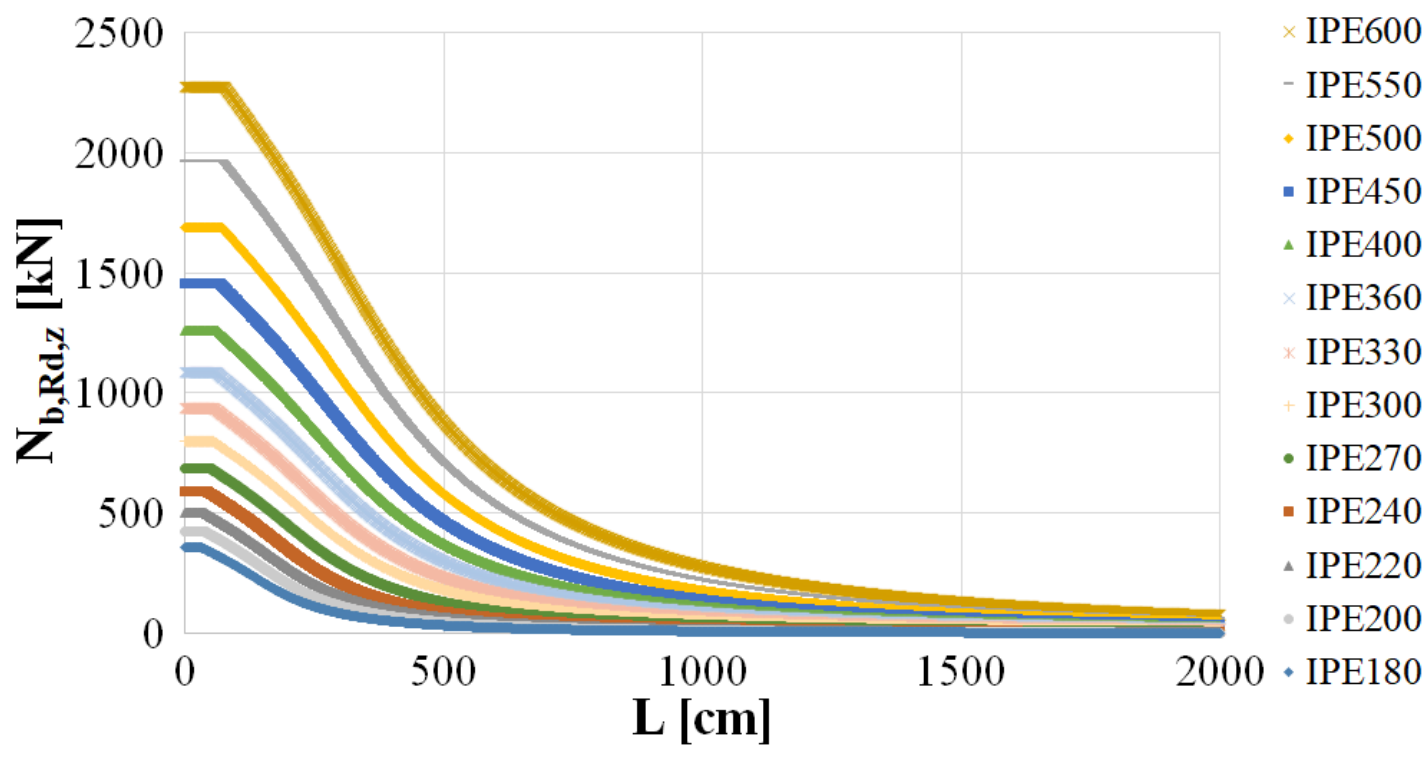

Fig. 7. Compression capacity of equivalent T-struts with different lengths composed of steel grade S355 [mm]

$h$ - height of base profile (e.g.IPE600: $h=600 \mathrm{~mm}$ )

$L$ - length of the haunch (formula is valid for $L>0$ mmand $L \leq 4000 \mathrm{~mm}$ ) $[\mathrm{mm}]$

The three formulas derived could be combined:

$$
\begin{gathered}
N_{b, R d, z, T-\text { profile }}=-\xi_{1} \times 10^{-4} \times h^{\alpha} \times L+0,06 \times h^{\beta} \leq \xi_{2} \times h-\xi_{3}[\mathrm{kN}] \\
\xi_{1}=6,75 \times \varepsilon^{2}-9,05 \times \varepsilon+3,90 \\
\xi_{2}=2,95 / \varepsilon^{2} \\
\xi_{3}=330 / \varepsilon^{2} \\
\alpha=-0,85 \times \ln (\varepsilon)+1,105(\alpha \approx-0,95 \times \varepsilon+2,055) \\
\beta=-0,4 \times \varepsilon+2 \\
\varepsilon=\left(235 / f_{y}\right)^{0,5}
\end{gathered}
$$

\subsection{Compression force in equivalent $T$-profile}

Formula (5) is valid for all the haunched zones listed at the beginning of the current subsection (fig.3). Naturally, if it is used in calculations, the compression force which is checked and deducted to this equivalent $T$-profile should be known. Therefore, the different geometric characteristics of the described profiles will be analyzed at the different eccentricities, respectively. 
The change of eccentricity defined by formula (1) will lead to the changes in the stress diagram in section 1 as illustrated in fig.2, and consequently to the variable compressed part of the stem. This would result in different stem heights (one-third of the compressed part of the stem is considered). Figure 8 illustrates the dependence between the eccentricity and the ratio of the geometric characteristics for the case under consideration and Figure 9 illustrates the dependence between the eccentricity and the ratio of the areas of the whole section and the equivalent $T$-section.

Nearly constant values of the geometric relationship are observed in function of the eccentricity of the inner axial force in the section located in the third from the large end of the bevelled section. Only with very small eccentricities (in the presence of a very high normal force compared to a bending moment), which is rather the standard case on a column, an increase in the geometric ratio is observed. This is because, when prevailing pressure, the equivalent $T$-profile has maximum dimensions - the larger part of the stem is compressed or the corresponding strut is bigger. Logically exactly the same is observed in the ratio of the area of the equivalent $T$-profile to the area of the entire cross-section (Fig.9).

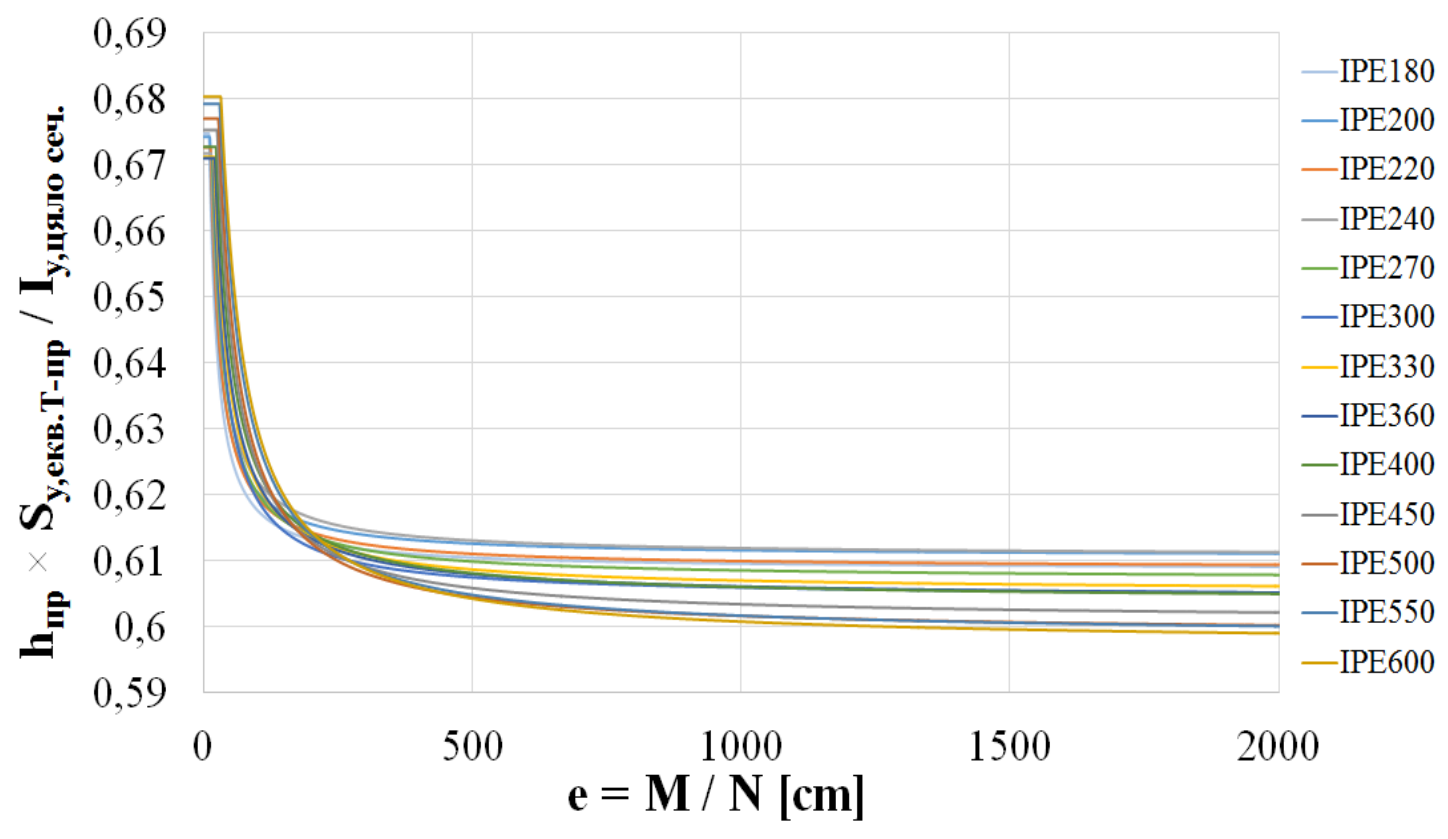

Fig. 8. Eccentricity in fuction of geometric charachteristics

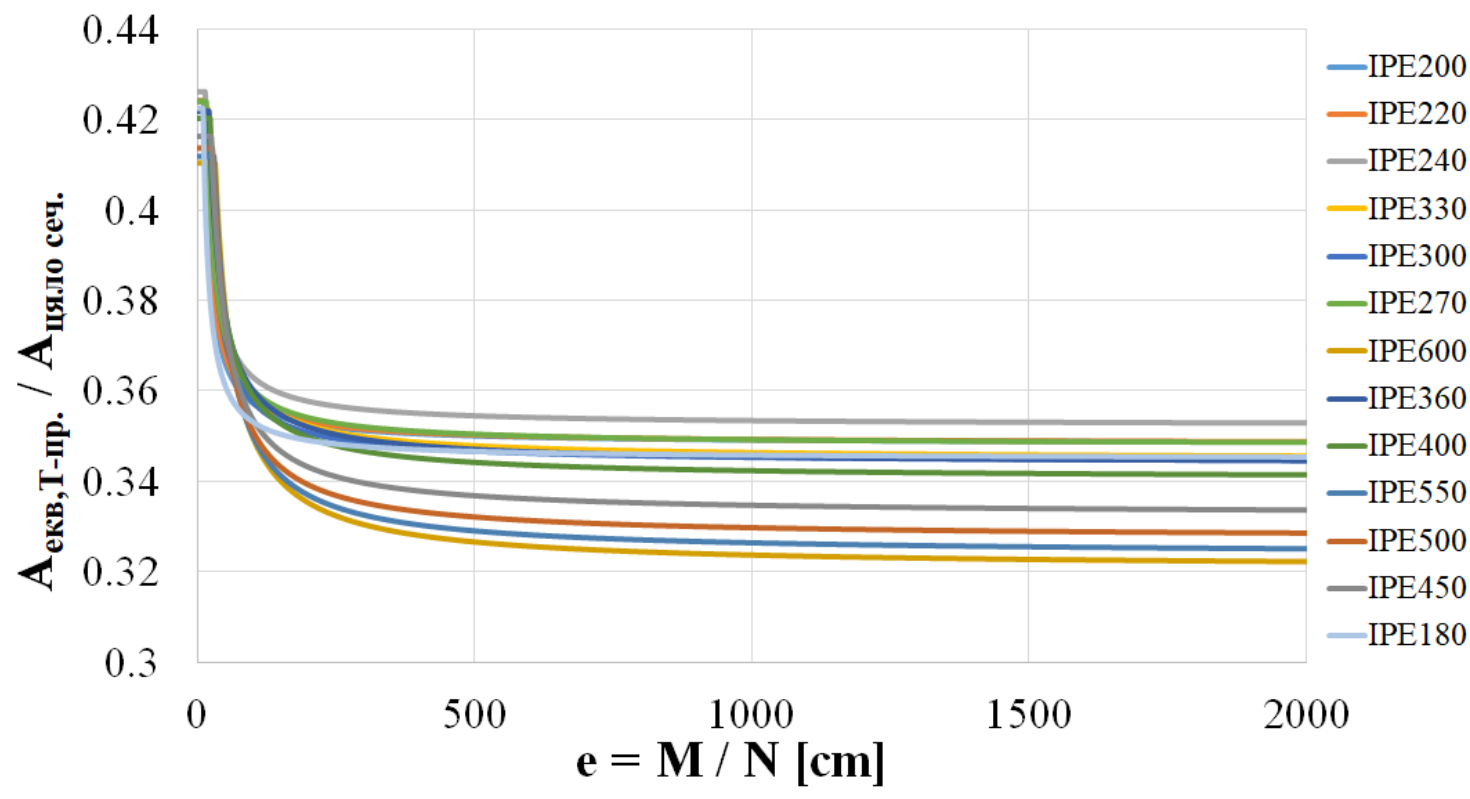

Fig. 9. Equivalent and base areas ratio in fuction of eccentricity 
From the graphs in Figure 8 it is possible to derive the multiplier for the computation moment in the cross section: $0,6 / h$ (all values are shown to be between 0.6 and 0.61) and Fig. 9 - the multiplier 0,35 for the deductible normal force. Thus, the final axial force with which to calculate the out of plane buckling of the equivalent $T$-profile results in the following pattern:

$N_{E d, \text { eqv.T-profile }}=0,35 \times N_{E d}+0,6 \times M_{E d} / h$ [mm]

$h$ - height of base profile (e.g.IPE600: $h=600 \mathrm{~mm}$ ) $N_{E d}$ - axial compression force in section 1 according to fig. $2[\mathrm{kN}]$

$M_{E d}$ - bending moment in section 1 according to fig.2[kNmm]

For low eccentricity $(e<200)$ axial compression force should raise with $15 \%$ :

$N_{E d, \text { eqv. } T \text {-profile }}=0,4 \times N_{E d}+0,7 \times M_{E d} / h$

\section{FINAL VERIFICATION}

It would be possible to apply the simplified methodology with the equivalent T-profile quickly and practically using these formulas when calculating the haunched segments of the most widely applied type with IPE-rolled profiles. The final procedure should be:

$N_{E d, \text { eqv.T-profile }}=0,35 \times N_{E d}+0,6 \times M_{E d} / h[k N]-u p$ with $15 \%$ fore $=M / N<200 \mathrm{~cm}$

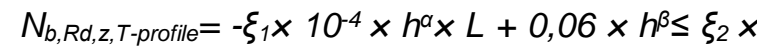
$h-\xi_{3}[k N]$

\section{REFERENCES}

[1] EN 1993-1-1: Eurocode 3: Design of steel structures. Part 1-1: General rules and rules for buildings, CEN, 2005.

[2] EN 1993-1-5: Eurocode 3: Design of steel structures. Part 1-5: Plated structural elements, CEN, 2006.

[3] Vassilev M., N. Rangelov. Stability problems of single storey steel frames (Part 1). Annual of UACEG, vol. 51(4), Sofia, 2018.

[4] Koschmidder D.M., D.G. Brown. Elastic design of single span steel portal frame buildings to Eurocode 3, SCI Publication P397, 2012.

[5] Simões da Silva, L., Simões, R., Gervásio, H. 2010. Design of Steel Structures. ECCS.
$N_{E d, \text { eqv.T-profile. }} / N_{b, R d, z, T \text {-profile }} \leq 1,00$.

$h$ - height of base profile (e.g.IPE600: $h=600 \mathrm{~mm}$ ) [mm]

$L$ - length of the haunch (formula is valid for $L>0$ mmand $L \leq 4000 \mathrm{~mm}$ ) [mm]

$N_{E d}$ - axial compression force in section 1 according to fig.2[kN]

$M_{E d}$ - bending moment in section 1 according to fig.2[kNmm]

$\xi_{1}, \xi_{2}, \xi_{3}, \alpha, \beta-$ according formulas (6) to (10).

\section{CONCLUSIONS}

There is no practical method for calculating tapered members in Eurocode 3 [1]. In author's opinion the easiest way for solving this problem is the widely spread practical method for calculating buckling capacity of haunch based on buckling verification of equivalent compressed strut, illustrated in Fig. 2. For the application of described method designer must calculate section properties such as second moment of area, buckling reduction factor etc. The simplified equivalent compressed strut model is proved to be suitable and conservative even without restraints to the bottom flange of the rafter.

Therefore simplified formulas are derived for the case of haunches, composed of IPE-profiles - very common case in practice. In this practical approach the only used parameters are height of the beam and material yield strength. Based on this two parameters verification of haunch member could be easily done.

[6] Penelov Č., A. Stojkov, P. Cvetkova. The application of the general method of EN1993-1-1 to stability evaluation of steel members which are within the scope of application of the standard method for members in compression and bending. Annual of UACEG, vol. XLVI-V, Sofia, 2013-14.

[7] Penelov Č., A. Stojkov, P. Cvetkova. The application of the general method of EN1993-1-1 to stability verification of steel tapered members in compression and bending. Annual of UACEG, vol. XLVI-V, Sofia, 2013-14.

[8] Abaqus, 2016. Dassault Systems / Simulia, Providence, RI, USA 


\section{METHOD FOR DETERMINATION OF LOAD-BEARING CAPACITY OF HAUNCHED ZONES MADE OF IPE- TYPE ROLLED}

\section{Marin VASSILEV}

Recently the author have conducted an extensive theoretical analysis programme on lateral stability of steel portal frames of hot-rolled profiles. Specific software has been developed for automatic modelling and applying the GMNIA method with a view to propose simple and reliable design rules for practical use.

A simplified method with equivalent compressed strut regarding haunched area was proven to be reliable. Therefore the author has analysed and simplified the method to make it easier to use.

Key words: Steel portal frames, Equivalent compressed strut, Haunch

\section{METOD ODREĐIVANJA NOSIVOSTI ZONE OJAČANJA (VUTA) IZRAĐENIH OD IPE TOPLO VALJANIH PROFILA}

\section{Marin VASSILEV}

Autor je sproveo opsežnu teorijsku analizu bočne stabilnosti čeličnih portalnih okvira toplo valjanih profila. Razvijen je poseban softver za automatsko modelovanje i primenu GMNIA metode s ciljem da se predlože jednostavna i pouzdana pravila projektovanja za praktičnu upotrebu. Dokazano je da je pojednostavljena metoda sa ekvivalentnim pritisnutim podupiračima u zoni vute pouzdana. Metod je analiziran i pojednostavljen kako bi bio lakši za primenu.

Ključne reči: Čelični portalni okviri , ekvivalentni pritisnuti podupirač, vuta 